\title{
Antimicrobial Susceptibility of Gram-Negative Bacteria in Brazilian Hospitals: The MYSTIC Program Brazil 2003
}

Carlos Kiffer $^{1}$, Andre Hsiung ${ }^{1}$, Carmen Oplustil ${ }^{1}$, Jorge Sampaio ${ }^{1}$, Elsa Sakagami ${ }^{1}$, Philip Turner ${ }^{2}$, Caio Mendes ${ }^{1}$, and the MYSTIC Brazil Group
Fleury Institute, Advisory Group on Antimicrobials and Clinical Microbiology ${ }^{l}$, São Paulo, Brazil; AstraZeneca Pharmaceuticals ${ }^{2}$, Macclesfield, Cheshire, England

Establish the susceptibility pattern of Gram-negative bacteria causing infections in ICU patients, MYSTIC Program Brazil 2003. Gram-negative bacteria $(n=1,550)$ causing nosocomial infections were collected at 20 Brazilian centers. The central laboratory confirmed the identification and performed the susceptibility tests by Etest methodology (AB Biodisk, Solna, Sweden) for meropenem, imipenem, ciprofloxacin, ceftazidime, cefepime, cefotaxime, piperacillin/tazobactam, gentamicin, and tobramycin. Interpretation criteria used were according to National Committee for Clinical Laboratory Standards (NCCLS). Pseudomonas aeruginosa $(\mathbf{3 0 . 3 \%})$ was the most frequent isolate, followed by $\boldsymbol{E}$. coli $(18.6 \%)$, Klebsiella pneumoniae (16.9\%), Acitenobacter baumannii (8.8\%), and Enterobacter cloacae (7.1\%). Pseudomonas aeruginosa $(\mathrm{n}=470)$ isolates presented susceptibility rates of $64 \%$ to meropenem, $63.8 \%$ to piperacillin/tazobactam, $63.4 \%$ to amikacin, $58.7 \%$ to imipenem. Acitenobacter baumannii presented susceptibility rates to meropenem of $97.1 \%$, and $73 \%$ to tobramycin. $E$. coli and $K$. pneumoniae were highly susceptible to both carbapenems. Carbapenem resistance among the Enterobacteriaceae is still rare in the region. Acitenobacter baumannii and $P$. aeruginosa presented elevated resistance rates to all antimicrobials. Since they play an important role in nosocomial infections in this environment, the use of empirical combination therapy to treat these pathogens may be justified.

Key Words: Drug resistance, bacterial, microbial sensitivity tests, infection control, carbapenems.

Amajor issue confronting organized health care today is that of controlling the increase in antimicrobial resistance [1-4]. Although multiple factors play a role in this problem, the selective pressures induced by inappropriate and widespread use of antibiotics are considered important contributors. Several studies have reported higher rates of antimicrobial resistance among isolates fromintensive care units (ICUs) than among isolates from general-patient-care areas [1,5-7]. These studies have provided important information about

Received on 10 January 2005; revised 07 June 2005.

Address for correspondence: Dr. Carlos R.V. Kiffer. Fleury Institute/Advisory Group on Antimicrobials and Clinical Microbiology. Avenida General Waldomiro de Lima 508, Zip code: 04344-070 - Jabaquara - São Paulo - SP - Brazil.Phone/ fax: +55 115014 7601.E-mail: carlos.kiffer@fleury.com.br

The Brazilian Journal of Infectious Diseases 2005;9(3):216-224 (C) 2005 by The Brazilian Journal of Infectious Diseases and Contexto Publishing. All rights reserved. changes in the spectrum of microbial pathogens and trends in antimicrobial resistance patterns in nosocomial and community-acquired infections along time. The information generated by surveillance programs, associated with an increased awareness about evolving resistance patterns, have proved helpful for the development of empirical approaches for the treatment of serious infections [8]. Additionally, surveillance programs may also be useful in the prevention and control of infections caused by resistant organisms [35,7-13]. Furthermore, surveillance programs have provided evidence of important differences in antimicrobial resistance patterns occurring in various geographical areas and even units within a certain area. However, those programs have a limited ability to identify and analyze all the relevant risk factors associated with the different resistance patterns.

The Meropenem Yearly Susceptibility Test Information Collection (MYSTIC) is a global, annual 
and multicenter surveillance program that compares the activity of several broad-spectrum antimicrobial agents in carbapenem user centers. MYSTIC Program Brazil was started in 1999, involving three centers (ICUs only); it was increased to seven centers in 2001 and 2002 (ICUs only), and matured to the present 2003 edition, with 20 centers (12 ICUS, 2 neutropenic patient units, and 6 general wards).

The objective of our study was to determine the susceptibility pattern of Gram-negative bacteria causing nosocomial infections in hospital patients, as part of the fourth edition of MYSTIC Program Brazil during 2003. It is our intention that these data could then be used locally, in conjunction with other related studies, to properly interpret significant resistance patterns and choose the most appropriate antimicrobial regimens for empirical therapy.

\section{Material and Methods}

Details of the study design and susceptibility testing methods have been previously described $[14,15]$.

\section{Participating Centers}

There were 19 participating centers during the 2003 program edition. All centers were asked to submit up to 100 Gram-negative bacteria samples, representative of the infectious process, regardless of the sample source, from specialized hospital units. All isolates were collected from January to October 2003 from hospitalized patients in 12 ICUs, 2 neutropenic patient units, and 6 general wards. Among the participating centers, 10 were located in southeastern (7 in São Paulo, 2 in Rio de Janeiro, 1 in Minas Gerais), 7 in southern (4 in Rio Grande do Sul, 2 in Paraná, 1 in Santa Catarina), 2 in northeastern (Bahia), and 1 in midwest Brazilian states (Brasilia) (Table 1).

\section{$\underline{\text { Isolates }}$}

One thousand five hundred and fifty Gram-negative bacilli responsible for the infectious process (according to the investigators) were randomly selected for inclusion in this study. Multiple isolates of the same species from a single origin (same patient) were excluded. Catheter, tracheal aspirates and bronchoalveolar lavage samples were submitted to semi-quantitative/quantitative cultures, accordingly. Each participating laboratory performed identification of microorganisms. The central laboratory (Fleury Diagnostics) confirmed the identification through conventional biochemical methodology or through the Vitek automated system.

\section{$\underline{\text { Susceptibility Tests }}$}

The central laboratory determined the minimum inhibitory concentrations (MICs) of meropenem, imipenem, ciprofloxacin, ceftazidime, cefepime, cefotaxime, piperacillin/tazobactam, gentamicin, tobramycin, and amikacin by Etest methodology (AB Biodisk, Solna, Sweden) and interpretations were made according to National Committee for Clinical Laboratory Standards (NCCLS) [16]. Control strains of $E$. coli (ATCC 25922), E. coli (ATCC 35218), and Pseudomonas aeruginosa (ATCC 27853) were tested with each set of MIC determinations.

$\underline{\text { Screening for Extended Spectrum } \beta \text {-Lactamase }}$ (ESBL)

E. coli and K. pneumoniae with MICs $\geq 2 \mu \mathrm{g} / \mathrm{mL}$ to any cephalosporins were submitted to an ESBL production test by double-disk synergy with amoxicillin/ clavulanic acid and ceftazidime, ceftriaxone, cefotaxime, and aztreonam. Isolates with an enhanced zone for any of these agents and amoxicillin/clavulanic acid were considered ESBL producers for the purpose of this report [17], since this test is not recommended by the NCCLS for confirmation of ESBL production. Control strains K. pneumoniae (ATCC 700603 ESBL positive) and E. coli (ATCC 25922 - ESBL negative) were assayed with each test set.

For the remaining species of Enterobacteriaceae, isolates that produced intermediate to resistant MICs to cefepime were interpreted as compatible with a 
phenotype of ESBL and AmpC producers. Strains with reduced susceptibility (Ior R) to cefotaxime and ceftazime but susceptible to cefepime, were submitted to the doubledisk synergy test to distinguish between AmpC hyperproduction and ESBL production phenotypes.

\section{Results}

$\underline{\text { Isolates }}$

The prevalence of microorganisms isolated and submitted to the central lab is shown in Table 2. Pseudomonas aeruginosa (30.3\%) was the most frequently-sent isolate, followed by $E$. coli (18.6\%), K. pneumoniae (16.9\%), A. baumannii (8.8\%), and Enterobacter cloacae (7.1\%).

\section{$\underline{\text { Sample Sources }}$}

Regarding sample source distribution, the most frequent samples were from urinary tract $(31.2 \%)$, followed by blood/catheter $(26.3 \%)$, respiratory tract (17.1\%) and intra-abdominal samples (2.9\%) (Table 3).

\section{$\underline{\text { Susceptibility Patterns }}$}

Table 4 shows the overall results of susceptibility pattern of $P$. aeruginosa, E. coli, K. pneumoniae, and A. baumannii.

\section{P. aeruginosa}

Pseudomonas aeruginosa $(\mathrm{n}=470)$ isolates had susceptibility rates of $64 \%$ to meropenem $\left(\mathrm{MIC}_{50} 1 \mu \mathrm{g} /\right.$ $\mathrm{mL}), 63.8 \%$ to piperacillin/tazobactam ( $\mathrm{MIC}_{50} 24 \mu \mathrm{g} /$ $\mathrm{mL}$ ), $63.4 \%$ to amikacin ( $\mathrm{MIC}_{50} 4 \mu \mathrm{g} / \mathrm{mL}$ ), $58.7 \%$ to imipenem $\left(\mathrm{MIC}_{50} 2 \mu \mathrm{g} / \mathrm{mL}\right), 58.3 \%$ to cefepime $\left(\mathrm{MIC}_{50} 6 \mu \mathrm{g} / \mathrm{mL}\right)$, and $55.8 \%$ to ceftazidime $\left(\mathrm{MIC}_{50}\right.$ $4 \mu \mathrm{g} / \mathrm{mL})$. Tobramycin, gentamicin and ciprofloxacin presented susceptibility rates $<55 \%$.

Susceptibility of $P$. aeruginosa per center is described in Table 5, with susceptibility rates shown for all 20 hospital units.
E. coli

E. coli $(\mathrm{n}=288)$ isolates were susceptible to both imipenem and meropenem $\left(\mathrm{MIC}_{90} 0.19\right.$ and $0.016 \mu \mathrm{g} /$ $\mathrm{mL}$, respectively), with susceptibility rates of $98.6 \%$ to piperacillin/tazobactam and amikacin, and $95.1 \%$ to ceftazidime. On the other hand, ciprofloxacin had a $76.7 \%$ susceptibility rate. Forty-two (14.6\%) isolates presented MICs of $\geq 2 \mathrm{mg} / \mathrm{mL}$ towards the cephalosporins and were submitted to a double-disk synergy test, which suggested production of ESBL. The frequency of ESBL producers varied greatly among centers, ranging from 0 to $83.3 \%$.

\section{K. pneumoniae}

Both carbapenems, imipenem and meropenem, presented $99.2 \%$ susceptibility rates against the $K$. pneumoniae $(\mathrm{n}=262)$ isolates $\left(\mathrm{MIC}_{90} 0.19\right.$ and $0.032 \mu \mathrm{g} / \mathrm{mL}$, respectively). The susceptibility rate to piperacillin/tazobactam was $87 \%\left(\mathrm{MIC}_{90} 32 \mu \mathrm{g} / \mathrm{mL}\right)$ and to $81.7 \%$ amikacin $\left(\mathrm{MIC}_{90} 32 \mu \mathrm{g} / \mathrm{mL}\right)$. All other drugs presented susceptibility rates below $65 \%$. ESBL production rate among $K$. pneumoniae was $51.9 \%$. Two strains yielded MICs in the intermediate and resistant range to meropenem. These isolates were both in the intermediate MIC range for imipenem. The isolates were forwarded for more detailed molecular analysis. The ESBL production rates among $K$. pneumoniae by centers showed frequencies ranging from $0 \%$ to $100 \%$.

\section{Acitenobacter baumannii}

Both carbapenems, imipenem and meropenem, presented $97.1 \%$ susceptibility rates against the $A$. baumannii $(\mathrm{n}=137)$ isolates evaluated $\left(\mathrm{MIC}_{50} 0.75\right.$ and $1 \mu \mathrm{g} / \mathrm{mL}$, respectively and $\mathrm{MIC}_{90} 2 \mu \mathrm{g} / \mathrm{mL}$ for both). The susceptibility rate to tobramycin was $73 \%\left(\mathrm{MIC}_{50}\right.$ $1.5 \mu \mathrm{g} / \mathrm{mL}$ and $\mathrm{MIC}_{90} 256 \mu \mathrm{g} / \mathrm{mL}$ ). All other drugs gave susceptibility rates below $55 \%$.

\section{Other Enterobacteriaceae}

When other Enterobacteriaceae were examined, both carbapenems (imipenem and 
Table 1. Number of isolates (n) and contribution (\%) per center - MYSTIC Program Brazil 2003

\begin{tabular}{crr}
\hline Center & \multicolumn{1}{c}{$\mathbf{N}$} & \% \\
\hline 1 & 97 & 6.3 \\
2 & 55 & 3.5 \\
4 & 83 & 5.3 \\
5 & 65 & 4.2 \\
6 & 59 & 3.8 \\
7 & 86 & 5.5 \\
8 & 74 & 4.8 \\
9 & 100 & 6.5 \\
10 & 43 & 2.8 \\
11 & 100 & 6.5 \\
12 & 77 & 5.0 \\
13 & 116 & 7.5 \\
14 & 96 & 6.2 \\
15 & 53 & 3.4 \\
16 & 118 & 7.6 \\
17 & 42 & 2.7 \\
18 & 100 & 6.5 \\
19 & 98 & 6.3 \\
20 & 35 & 2.3 \\
Total & $\mathbf{1 , 5 5 0}$ & $\mathbf{1 0 0}$ \\
\hline
\end{tabular}

Table 2. Prevalence of microorganisms isolated

\begin{tabular}{lrr}
\hline Microorganism & $\mathbf{N}$ & $\mathbf{\%}$ \\
\hline P. aeruginosa & 470 & 30.3 \\
E. coli & 288 & 18.6 \\
K. pneumoniae & 262 & 16.9 \\
A. baumannii & 137 & 8.8 \\
E. cloacae & 110 & 7.1 \\
P. mirabilis & 51 & 3.3 \\
S. maltophilia & 42 & 2.7 \\
S. marcescens & 38 & 2.5 \\
E. aerogenes & 23 & 1.5 \\
C. freundii & 21 & 1.3 \\
K. oxytoca & 12 & 0.8 \\
M. morganii & 12 & 0.8 \\
Others & 84 & 5.4 \\
Total & $\mathbf{1 , 5 5 0}$ & $\mathbf{1 0 0}$ \\
\hline
\end{tabular}

Table 3. Frequency of microorganisms per main sample source

\begin{tabular}{lcccc}
\hline Microorganism & Blood/Catheter & $\begin{array}{c}\text { N }(\%) \\
\text { Respiratory tract }\end{array}$ & Urinary tract & Skin/Soft tissue \\
\hline P. aeruginosa & $116(28.5)$ & $121(45.7)$ & $106(21.9)$ & $48(36.9)$ \\
E. coli & $32(7.9)$ & $17(6.4)$ & $162(33.5)$ & $23(17.7)$ \\
K. pneumoniae & $70(17.2)$ & $32(12.0)$ & $90(18.6)$ & $15(11.5)$ \\
A. baumannii & $68(16.7)$ & $24(9.1)$ & $23(4.8)$ & $10(7.7)$ \\
E. cloacae & $33(8.1)$ & $12(4.5)$ & $40(8.3)$ & $7(5.4)$ \\
P. mirabilis & $12(2.9)$ & $4(1.5)$ & $24(5.0)$ & $4(3.1)$ \\
Others & $76(18.7)$ & $55(20.8)$ & $38(7.9)$ & $23(17.7)$ \\
Total & $\mathbf{4 0 7}(\mathbf{1 0 0})$ & $\mathbf{2 6 5 ( 1 0 0 )}$ & $\mathbf{4 8 3}(\mathbf{1 0 0})$ & $\mathbf{1 3 0}(\mathbf{1 0 0})$ \\
\hline
\end{tabular}


Table 4. Susceptibility pattern of $P$. aeruginosa, E. coli, K. pneumoniae, and A. baumannii - MYSTIC Program Brazil 2003

\begin{tabular}{|c|c|c|c|c|c|}
\hline \multirow[b]{2}{*}{ Species/antimicrobial } & \multicolumn{3}{|c|}{$\%$} & \multicolumn{2}{|c|}{$\mu \mathrm{g} / \mathrm{mL}$} \\
\hline & $\mathbf{S}$ & $\mathbf{I}$ & $\mathbf{R}$ & $\mathrm{MIC}_{50}$ & $\mathrm{MIC}_{90}$ \\
\hline \multicolumn{6}{|l|}{ P. aeruginosa $(\mathrm{n}=470)$} \\
\hline Cefepime & 58.3 & 11.7 & 30 & 6 & $>256$ \\
\hline Ceftazidime & 55.8 & 5.5 & 36 & 4 & $>256$ \\
\hline Imipenem & 58.7 & 4.7 & 36.6 & 2 & $>32$ \\
\hline Meropenem & 64 & 2.1 & 33.9 & 1 & $>32$ \\
\hline Piperacillin/tazobactam & 63.8 & 0 & 36.2 & 24 & $>256$ \\
\hline Ciprofloxacin & 49.6 & 2.1 & 48.3 & 1.5 & $>32$ \\
\hline Gentamicin & 53.2 & 2.5 & 44.3 & 4 & $>256$ \\
\hline Tobramycin & 54 & 4 & 42 & 1.5 & $>256$ \\
\hline Amikacin & 63.4 & 2.8 & 33.8 & 4 & $>256$ \\
\hline \multicolumn{6}{|l|}{ E. $\operatorname{coli}(\mathrm{n}=288)$} \\
\hline Cefepime & 85.4 & 0 & 14.6 & 0.032 & 6 \\
\hline Ceftazidime & 85.4 & 0 & 14.6 & 0.19 & 3 \\
\hline Cefotaxime & 85.4 & 0 & 14.6 & 0.064 & 64 \\
\hline Imipenem & 100 & 0 & 0 & 0.19 & 0.25 \\
\hline Meropenem & 100 & 0 & 0 & 0.016 & 0.032 \\
\hline Piperacillin/tazobactam & 98.6 & 1 & 0.4 & 2 & 4 \\
\hline Ciprofloxacin & 76.7 & 2.1 & 21.2 & 0.006 & $>32$ \\
\hline Gentamicin & 88.2 & 2.8 & 9 & 0.5 & 8 \\
\hline Tobramycin & 88.9 & 3.5 & 7.6 & 0.75 & 8 \\
\hline Amikacin & 98.6 & 0 & 1.4 & 1.5 & 3 \\
\hline \multicolumn{6}{|c|}{ K. pneumoniae $(\mathrm{n}=262)$} \\
\hline Cefepime & 48.1 & 0 & 51.9 & 1 & 48 \\
\hline Ceftazidime & 48.1 & 0 & 51.9 & 1 & 48 \\
\hline Cefotaxime & 48.1 & 0 & 51.9 & 4 & $>256$ \\
\hline Imipenem & 99.2 & 0.8 & 0 & 0.19 & 0.25 \\
\hline Meropenem & 99.2 & 0.4 & 0.4 & 0.032 & 0.094 \\
\hline Piperacillin/tazobactam & 87 & 5.7 & 7.3 & 4 & 32 \\
\hline Ciprofloxacin & 64.1 & 5.7 & 30.2 & 0.125 & $>32$ \\
\hline Gentamicin & 52.3 & 13.4 & 34.3 & 2 & 128 \\
\hline Tobramycin & 53 & 11.5 & 35.5 & 3 & 48 \\
\hline Amikacin & 81.7 & 11.8 & 6.5 & 2 & 32 \\
\hline \multicolumn{6}{|l|}{ A. baumannii $(\mathrm{n}=137)$} \\
\hline Cefepime & 33.6 & 19.7 & 46.7 & 24 & $>256$ \\
\hline Ceftazidime & 31.4 & 9.5 & 59.1 & 64 & $>256$ \\
\hline Imipenem & 97.1 & 0 & 2.9 & 0.75 & 2 \\
\hline Meropenem & 97.1 & 0 & 2.9 & 1 & 2 \\
\hline Piperacillin/tazobactam & 32.1 & 12.4 & 55.5 & 256 & $>256$ \\
\hline Ciprofloxacin & 34.3 & 0 & 65.7 & $>32$ & $>32$ \\
\hline Gentamicin & 53.3 & 19 & 27.7 & 4 & $>256$ \\
\hline Tobramycin & 73 & 9.5 & 17.5 & 1.5 & 256 \\
\hline Amikacin & 36.5 & 5.8 & 57.7 & 128 & $>256$ \\
\hline
\end{tabular}


Table 5. Susceptibility (\%) of P. aeruginosa isolates per center-MYSTIC Program Brazil 2003

\begin{tabular}{|c|c|c|c|c|c|c|c|c|c|c|}
\hline \multirow[b]{2}{*}{ Center } & \multirow[b]{2}{*}{$\mathbf{n}$} & \multicolumn{9}{|c|}{ \% Susceptible } \\
\hline & & CEP & $\mathbf{C A Z}$ & IMP & MEM & PTZ & CIP & GM & TB & $\mathbf{A K}$ \\
\hline 1 & 40 & 12.5 & 12.5 & 10 & 12.5 & 35 & 10 & 12.5 & 10 & 32.5 \\
\hline 2 & 17 & 94.1 & 94.1 & 88.2 & 94.1 & 94.1 & 88.2 & 88.2 & 88.2 & 88.2 \\
\hline 4 & 21 & 66.7 & 66.7 & 61.9 & 66.7 & 66.7 & 61.9 & 57.1 & 61.9 & 61.9 \\
\hline 5 & 26 & 50 & 50 & 19.2 & 42.3 & 46.2 & 19.2 & 23.1 & 23.1 & 57.7 \\
\hline 6 & 19 & 52.6 & 47.4 & 52.6 & 52.6 & 47.4 & 31.6 & 57.9 & 52.6 & 52.6 \\
\hline 7 & 23 & 56.5 & 39.1 & 69.6 & 69.6 & 47.8 & 56.5 & 56.5 & 56.5 & 60.9 \\
\hline 8 & 28 & 50 & 60.7 & 53.5 & 57.1 & 60.7 & 46.4 & 67.9 & 78.6 & 78.6 \\
\hline 9 & 25 & 68 & 68 & 76 & 76 & 64 & 60 & 64 & 60 & 64 \\
\hline 10 & 10 & 100 & 80 & 100 & 100 & 90 & 70 & 70 & 70 & 90 \\
\hline 11 & 16 & 87.5 & 87.5 & 93.8 & 100 & 100 & 93.8 & 81.3 & 87.5 & 100 \\
\hline 12 & 40 & 60 & 60 & 60 & 70 & 65 & 45 & 57.5 & 50 & 60 \\
\hline 13 & 63 & 69.8 & 71.4 & 71.4 & 76.2 & 73 & 69.8 & 68.3 & 71.4 & 73 \\
\hline 14 & 22 & 31.8 & 31.8 & 50 & 50 & 54.5 & 22.7 & 22.7 & 22.7 & 36.4 \\
\hline 15 & $7 *$ & 28.6 & 14.3 & 28.6 & 28.6 & 42.9 & 14.3 & 14.3 & 28.6 & 28.6 \\
\hline 16 & 43 & 62.8 & 55.8 & 58.1 & 62.8 & 65.1 & 53.5 & 53.5 & 55.8 & 72.1 \\
\hline 17 & 14 & 57.1 & 57.1 & 71.4 & 71.4 & 78.6 & 71.4 & 71.4 & 71.4 & 71.4 \\
\hline 18 & 15 & 40 & 100 & 93.3 & 93.3 & 60 & 33.3 & 40 & 40 & 53.3 \\
\hline 19 & 17 & 52.9 & 52.9 & 47.1 & 52.9 & 70.6 & 47.1 & 47.1 & 47.1 & 64.7 \\
\hline 20 & $5^{*}$ & 60 & 40 & 40 & 40 & 40 & 0 & 0 & 0 & 0 \\
\hline 21 & 19 & 94.7 & 94.7 & 68.4 & 89.5 & 89.5 & 68.4 & 73.7 & 78.9 & 78.9 \\
\hline Total & 470 & 58.3 & 58.5 & 58.7 & 64 & 63.8 & 49.6 & 53.2 & 54 & 63.4 \\
\hline & & & IMP & Imip & & PTZ & & . & & \\
\hline CAZ & & & MEM & Mero & & CIP & Cipr & icin & & \\
\hline GM & Getam & & $\mathrm{TB}$ & Tobram & & AK & Amil & & & \\
\hline
\end{tabular}

meropenem) gave $100 \%$ susceptibility rates against isolates of Citrobacter spp., Enterobacter spp., Serratia spp., and Providencia spp. Among Citrobacter freundii isolates, 52\% (11/21) presented resistance to extended-spectrum cephalosporins, with a phenotype suggestive of a chromosomal AmpC hyperproducer. Among $E$. cloacae $(\mathrm{n}=110)$ isolates, $42(38 \%)$ presented resistance to extended-spectrum cephalosporins, with a phenotype suggestive of chromosomal AmpC hyperproducer. Additionally, 27 of those 42 presented resistance to cefepime, also suggesting ESBL production. Among Enterobacter aerogenes $(\mathrm{n}=23)$ isolates, $7(30 \%)$ were consistent with a phenotype of AmpC hyperproduction, and 3 (13\%) of those were also suggestive of ESBL production. Among Serratia marcescens $(\mathrm{n}=38)$ isolates, $12(32 \%)$ were consistent with a phenotype of AmpC hyperproduction, and 4 (11\%) of those were also suggestive of ESBL production. Among Proteus mirabilis $(\mathrm{n}=51)$ and Morganella morganii $(\mathrm{n}=12)$ isolates, $11(22 \%)$ and $3(25 \%)$, respectively, presented phenotypes suggestive of ESBL production, conferring resistance to third and fourth generation cephalosporins. 


\section{Discussion}

The MYSTIC Program is a large-scale surveillance program of nosocomial bacterial isolates with associated information on their MICs. Our data was collected from patients hospitalized in 20 hospitals located in eight Brazilian states during the 2003 edition of the program. The program's main objective was to evaluate the susceptibility pattern of Gram-negative bacilli isolated from patients with nosocomial infections. This is in accordance with the fundamentals of other microbiological surveillance studies, since these studies aim to identify regional patterns of resistance in specific settings. Surveillance programs also play a role as major contributors to guiding empirical antimicrobial therapy $[8,9]$. However, these programs are limited in their ability to answer all relevant clinical and microbiological outcome issues for all world regions, thus reinforcing the need for regional data.

Pseudomonas aeruginosa was the most frequently submitted isolate, accounting for $30.3 \%$ of all isolates, followed by E. coli (18.6\%), K. pneumoniae (16.9\%), A. baumannii (8.8\%), and E. cloacae $(7.1 \%)$. The frequency of $P$. aeruginosa and $A$. baumannii has risen significantly, when compared to the first MYSTIC edition in Brazil [18], but it has remained rather constant since the previous editions in 2001 [19] and 2002 (in press). Even with the increase in participating centers as compared to the 2001 and 2002 editions, the frequency of $P$. aeruginosa isolates has remained constant at around $30 \%$. This may be due to the characteristics of the participating centers, which may be similar, and to the exclusive isolation of Gramnegative bacteria during all three years. It should also be noted that, similar to the previous edition, at least $57.4 \%$ of samples in the present edition were from clinically significant sources and definitely related to the infectious process (blood, catheter and urinary tract). However, $17.1 \%$ of samples were from the respiratory tract, although always considered by investigators as causative agents of the infectious processes. Nevertheless, one cannot completely rule out the contribution of colonizers as part of the total amount of isolates. The higher number of isolates from blood/ catheter was expected, since our study did not aim at establishing the prevalence of nosocomial infections. But rather, the study aimed at isolating clinicallysignificant bacteria causative of the infectious processes.

The susceptibility patterns detected by the MYSTIC Program 2003, particularly for meropenem against $P$. aeruginosa and A. baumannii, in these 20 Brazilian centers demonstrated resistance rates somewhat higher than the ones determined by other studies $[4,6,7,12,20,21]$, although lower than the ones detected in the 2002 program. The present MYSTIC edition in Brazil showed $36 \%$ resistance rate to meropenem in $P$. aeruginosa isolates, while the previous 2002 edition showed $40.2 \%$ (in press), and the others showed resistance rates to carbapenems in $P$. aeruginosa and $A$. baumannii ranging between 18$21 \%$ and $14-15 \%$, respectively $[18,19]$. Possible reasons for the higher resistance patterns observed during 2002 and 2003, when compared to other editions and to other surveillances, could be based on the program's selection of carbapenem user hospital units and of specialized centers, particularly with an increased number of intensive care units during 2003. Other possible reasons could also be that the centers, although scattered around the country, were all major reference hospitals with specialized units. This may reflect a specific influence of demographic characteristics of these units in the high resistance rates obtained. Furthermore, clonal spread among $P$. aeruginosa and $A$. baumannii was confirmed during the 2002 program edition, with documented clonal spread within the same centers and among different centers, even in different city locations [22,23].

Pseudomonas aeruginosa $(\mathrm{n}=470)$ isolates presented high resistance rates against all antimicrobials, with descending order of susceptibility rates of $64 \%$ to meropenem ( $\left.\mathrm{MIC}_{50} 1 \mu \mathrm{g} / \mathrm{mL}\right), 63.8 \%$ to piperacillin/ tazobactam $\left(\mathrm{MIC}_{50} 24 \mu \mathrm{g} / \mathrm{mL}\right), 63.4 \%$ to amikacin $\left(\mathrm{MIC}_{50} 4 \mu \mathrm{g} / \mathrm{mL}\right), 58.7 \%$ to imipenem $\left(\mathrm{MIC}_{50} 2 \mu \mathrm{g} /\right.$ $\mathrm{mL}), 58.3 \%$ to cefepime $\left(\mathrm{MIC}_{50} 6 \mu \mathrm{g} / \mathrm{mL}\right)$, and $55.8 \%$ to ceftazidime $\left(\mathrm{MIC}_{50} 4 \mu \mathrm{g} / \mathrm{mL}\right)$. Significant differences in resistance rates were observed among the centers from different regions, but in our analysis it was not 
possible to identify an underlying spatial pattern. Thus one cannot say if the resistance patterns to most antimicrobials are actually spatially random, as they appear to be. Susceptibility of $P$. aeruginosa varied greatly among centers, with rates ranging from $90 \%$ to $100 \% \mathrm{~S}$ for carbapenems and piperacillin/tazobactam in centers 2, 10 and 11 to $<55 \%$ for all antimicrobials in centers 1, 5 and 14. As previously discussed, clonal spread may have contributed to the susceptibility observed in specific centers.

On the other hand, A. baumannii $(\mathrm{n}=137)$ isolates presented susceptibility rates to imipenem and meropenem of $97.1 \%\left(\mathrm{MIC}_{50} 0.75\right.$ and $1 \mu \mathrm{g} / \mathrm{mL}$, respectively and $\mathrm{MIC}_{90} 2 \mu \mathrm{g} / \mathrm{mL}$ for both), and $73 \%$ to tobramycin ( $\mathrm{MIC}_{50} 1.5 \mu \mathrm{g} / \mathrm{mL}$ ), which is in accordance with previous MYSTIC editions in the country (18, 19). E. coli ESBL producing isolates (14.6\%) presented a similar prevalence, when compared to the 2002 edition (13.7\%) and to other previous editions of the study [19,20]. Among these 42 isolates with MICs $\geq 2 \mu \mathrm{g} / \mathrm{mL}$ towards the cephalosporins and confirmed as ESBL producers, the results of the screening showed that cefotaxime was a highly-sensitive agent for this screening. This finding suggests the predominance of CTX enzymes in Brazil.

Klebsiella pneumoniae ESBL-producing isolates $(51.9 \%)$ had a higher prevalence when compared to the 2002 edition $(37.7 \%)$ and lower than the 2001 edition $(63.5 \%)$ [18]. Similar to E. coli, cefotaxime was also the most sensitive ESBL screening agent. A tendency analysis will be reported separately. However, some factors may have contributed to the observed variation, particularly in the rates of $K$. pneumoniae ESBL-producing isolates. Clonal spread involving $K$. pneumoniae ESBL-producing isolates cannot be ruled out within and among participating centers, contributing to the observed rates. Nevertheless, one cannot exclude the possibility of a selection bias in the samples, since ours was not a prevalence defining study. Two strains yielded MICs in the intermediate resistance range to meropenem. These isolates were both in the intermediate MIC range for imipenem. The isolates were sent out for more detailed molecular analysis.
In conclusion, resistance development to antimicrobials is currently a major concern for the medical community worldwide, since infections caused by resistant bacteria seem to be associated with worsened morbidity factors (hospitalization, death and illnesses rates) [24]. The implementation of monitoring programs is an important part of the prevention strategy against the progression of resistance. Surveillance in specific units apparently offers a unique opportunity to detect the emergence of resistance in bacteria used as sentinel agents, especially in units with higher antibiotic usage density $[1,25]$. Our study confirms previous findings that carbapenem resistance among Enterobacteriacea is still rare in the region [4,6,7,12,18,19,21-23]. On the other hand, $A$. baumannii and $P$. aeruginosa have been particularly problematic organisms in Brazil, because of their prevalence and resistance patterns. Since $A$. baumannii and $P$. aeruginosa play an important role in nosocomial infections in this environment, as determined by this and other studies $[6,7,12,18,19,21$ 23 ], added to the facts that they did not present high susceptibility rates to any of the drugs, and because no single regimen had a high target attainment on a Monte Carlo simulation program based on the similar data [26], the use of empirical combination therapy to treat these pathogens may be justified in selected centers (i.e. those with high resistance rates to carbapenems).

\section{MYSTIC Brazil Group}

Marcelo Marotti, Jorge B. Amarante, Antonio C. C. Pignatari, Soraya Andrade, Cássia M. Zocolli, Jorge D. de Mattos, Marinês D. Martino, Luis F. Camargo, Adília Segura, Julival Ribeiro, Lycia Mimica, Sueli Ykko, Maria Rita E. de Araújo, Guilherme Schettino, Carlos J. Lotfi, Marisa Santos, Márcia Vasques, Marcelo R. Schirmer, Lucia Farias, Líbera M. Dalla Costa, Clóvis A. Cunha, Carlos F. Starling, José A. Ferreira, Joseani C. P. Garcia, Emerson Cavassin, Goreth Barberino, José F. Silva, Afonso L. Barth, Tereza C. T. Sukiennik, Ana L. S. Gonçalves, Cláudio M. B. Stadnik, Cícero Dias, Áurea A. Paste. 


\section{References}

1. Mendes C., Turner P.J. Unit differences in pathogen occurrence among European MYSTIC Program (19972000). Diagn Microbiol Infect Dis 2001;41:191-6.

2. Archibald L., Phillips D., Monnet D., et al. Antimicrobial resistance in isolates from inpatients and outpatients in the United States: increasing importance of the intensive care unit. Clin Infect Dis 1997;24:211-5.

3. Jones R.N. The emergent needs for basic research, education, and surveillance of antimicrobial resistance. Problems facing the report from the American Society for Microbiology Task Force on Antibiotic Resistance. Diagn Microbiol Infect Dis 1996;25:153-61.

4. Jones R.N., Pfaller M.A. Bacterial resistance: a worldwide problem. Diagn Microbiol Infect Dis 1998;31:379-88.

5. Pfaller M.A., Jones R.N., Biedenbach D.J. MYSTIC Program Study Group (USA). Antimicrobial resistance trends in carbapenem prescribing medical units: report of the 1999 and 2000 results from MYSTIC Program (USA). Diagn Microbiol Infect Dis 2001;41(4):177-82.

6. Diekema D.J., Pfaller M.A., Jones R.N., et al. Survey of bloodstream infection due to Gram-negative bacilli: frequency of occurrence and antimicrobial susceptibility of isolates collected in the United States, Canada and Latin America for the SENTRY Antimicrobial Surveillance Program. 1997. Clin Infect Dis 1997;29:595-607.

7. Diekema D.J., Pfaller M.A., Jones R.N., et al. Trends in antimicrobial susceptibility of bacterial pathogens isolated from patients with bloodstream infection in the USA, Canada and Latin America. Int J Antimicrob Agents 2000;13:257-71.

8. Masterton R.G. Surveillance studies: how can they help the management of infection? J Antimicrob Chemother 2000;46(T2):53-8.

9. Jones R.N. Detection of emerging resistance patterns within longitudinal surveillance systems: data sensitivity and microbial susceptibility. J Antimicrob Chemother 2000;46(topic T2):1-8.

10. Jones R.N. Contemporary antimicrobial susceptibility patterns of bacterial pathogens commonly associated with febrile patients with neutropenia. Clin Infect Dis 1999;29:495-502.

11. Pfaller M.A., Jones R.N., Doern G.V., Kugler K.C. Bacterial pathogens isolated from patients with bloodstream infection: frequencies of occurrence and antimicrobial susceptibility patterns from the SENTRY Antimicrobial Resistance Surveillance Program (United States and Canada). Antimicrob Agents Chemother 1998;42:1762-70.

12. Sader H.S., Jones R.N., Winokur P.L. Antimicrobial susceptibility of bacteria causing urinary tract infections in Latin American hospitals: results from the SENTRY Antimicrobial Surveillance Program (1997). Clin Microbiol Infect 1999;5:478-87.
13. Jones R.N., Masterton R. Establishing the value of antimicrobial surveillance programs. Diagn Microbiol Infect Dis 2001;41:171-5.

14. Turner P.J. MYSTIC (Meropenem Yearly Susceptibility Test Information Collection): a global overview. J Antimicrob Chemother 2000;46(T2):9-23.

15. Rhomberg P.R., Jones R.N., The MYSTIC Program (USA) Study Group.. Antimicrobial spectrum of activity for meropenem and nine broad spectrum antimicrobials: report from the MYSTIC Program (2002) in North America. Diagn Microbiol Infect Dis 2003;47:365-72.

16. NCCLS. Performance Standards for Antimicrobial Susceptibility Testing: eleventh informational supplement M100-S13. NCCLS, Wayne, Pa, 2003.

17. Legrand P., Fournier G., Bure A., et al. Detection of extended broad-spectrum beta-lactamases in Enterobacteriaceae in four French hospitals. Eur J Clin Microbiol Infect Dis 1989;8(6):527-9.

18. Mendes C., Hsiung A., Kiffer C., et al. Evaluation of in vitro Activity of 9 Antimicrobials Against Bacterial Strains Isolated From Patients in Intensive Care Units in Brazil: MYSTIC Antimicrobial Surveillance Program. Braz J Inf Dis 2000;4(5):236-44.

19. Mendes C., Oplustil C., Turner P., et al. Antimicrobial susceptibility in intensive care units: MYSTIC Program Brazil 2001. XI Congreso Panamericano de Infectologia, 11-14 May, Cordoba, Argentine, 2003.

20. Jones R.N. Resistance Patterns Among Nosocomial Pathogens: Trends Over the Past Few Years. Chest 2001;119(S2):397S-404S.

21. Sader H.S., Jones R.N., Gales A.C., et al. Antimicrobial susceptibility patterns for pathogens isolated from patients in Latin American medical centers with a diagnosis of pneumonia: analysis of results from the SENTRY Antimicrobial Surveillance Program (1997): SENTRY Latin America Study Group. Diagn Microbiol Infect Dis 1998;32:289-301.

22. Mendes C., Sinto S., Sampaio J., et al. P. aeruginosa clonal dissemination in Brazilian intensive care units during 2002. Clin Microbiol Infect 2004;10(S3): 300.

23. Mendes C., Sinto S., Sampaio J., et al. A. baumannii clonal dissemination in Brazilian intensive care units during 2002. Clin Microbiol Infect 2004;10(S3):439.

24. Scheld W.M. Maintaining fluoroquinolone class efficacy: review of influencing factors. Emerg Inf Dis 2003;9(1):1-9.

25. Pfaller M.A., Jones R.N., Biedenbach D.J. MYSTIC Program Study Group (USA). Antimicrobial resistance trends in carbapenem prescribing medical units: report of the 1999 and 2000 results from MYSTIC Program (USA). Diagn Microbiol Infect Dis 2001;41(4):177-82.

26. Kiffer C.R.V., Mendes M., Kuti J.L., Nicolau D.P. Pharmacodynamic Comparisons of Antimicrobials Against Nosocomial Isolates of E. coli, K. pneumoniae, A. baumannii and $P$. aeruginosa from the MYSTIC Surveillance Program: The OPTAMA Program, South America 2002. Diag Microbiol Inf Dis 2004;49:109-16. 